Kateřina Ritterová (D) Universidade Palacký de Olomouc katerina.ritterova@upol.cz

\title{
Adília do Outro Lado do Espelho (o lírico e o grotesco na poesia de Adília Lopes) ${ }^{1}$
}

\section{Resumo:}

Este breve estudo tem como objetivo seguir as vias e as variedades do humor na poesia da escritora portuguesa contemporânea Adília Lopes. A poética adiliana é muito específica: à primeira vista não é poesia ligada à beleza ou à ternura. A própria poetisa fala da sua poesia como de poesia prosaica ou poesia do quotidiano. $\mathrm{O}$ estudo mostra que a poética de Adília Lopes tem o seu lado de beleza e de ternura, já que desnuda a vida humana através do humor negro, mas de uma maneira benévola, se bem que de um lado que nem sempre queremos ver ou que pode estar longe de nos agradar. A análise seguirá as possibilidades da criação de situações grotescas e sensações de ternura e de horror, que causam riso e arrepio ao mesmo tempo. $\mathrm{O}$ trabalho está dividido em partes, segundo o modo como a poetisa consegue o efeito cómico - banalização dos chamados grandes temas: amor, morte e solidão, anedotas poéticas e banalização das obras literárias mitificadas. $\mathrm{Na}$ análise dos poemas escolhidos prova-se que a poesia de Adília Lopes, ainda que bastante crua e às vezes até cruel, possui um encanto inédito, muito próximo da poética de Alice no País das Maravilhas. Tanto das personagens de Alice como das personagens de Adília emanam certas características do grotesco, de forma simultaneamente lírica e feérica.

Palavras-chave: Adília Lopes, poesia portuguesa, humor, grotesco, ironia

${ }^{1} \mathrm{O}$ artigo foi publicado no âmbito do projeto do Ministério da Educação da República Checa IGA FF 2018015. 


\begin{abstract}
:
Adília Through the Looking-Glass (Lyricism and Grotesque in Adília Lopes's Poetry)

This brief study aims to follow the pathways and varieties of humour in the poetry of the contemporary Portuguese writer Adília Lopes. Her poetry is very specific and, at first sight/reading, it is not the sort of poetry connected with beauty or tenderness. The poetess herself speaks of her poetry as prosaic poetry or poetry of everyday life. The study shows that the poetry of Adília Lopes has its side of beauty and tenderness, since it strips human life through black humour, but in a benevolent way, although we may not always want to see life portrayed like that and such descriptions may thus be far from pleasing us. Our analysis will follow the possibilities of creating grotesque situations and sensations of tenderness and horror likely to cause laughter and shiver at the same time. Our work is divided into parts according to how the poetess achieves the comic effect - banalization of the so-called great subjects: love, death, solitude, poetic anecdotes and the trivialization of mythical poems. In the analysis of the chosen poems, we intend to show that, despite being rather crude and sometimes even cruel, Adília Lopes's poetry possesses an unprecedented charm, very close to the poetic atmosphere in Alice in Wonderland. Both the characters in Alice and those in Adília's work reveal certain characteristics of the grotesque, but not without lyrical and fairytalistic counterparts.
\end{abstract}

Keywords: Adília Lopes, portuguese poetry, humor, grotesque, irony

\title{
Introdução - O fenómeno Adília Lopes
}

O humor na poesia é algo muito raro e ao mesmo tempo - há que convir - muito refrescante. A obra da poetisa portuguesa Adília Lopes é repleta de humor negro, irónico, às vezes infantil, outras vezes um pouco cruel. Pretendemos seguir neste estudo as variedades do humor adiliano e mostrar que até o grotesco pode estar ligado ao lírico e o irónico ao romântico na poesia desta extraordinária autora.

Adília Lopes é o pseudónimo, mais precisamente um projeto literário ou um sujeito lírico bem trabalhado, da poetisa Maria José da Silva Viana Fidalgo de Oliveira, nascida em 1960, formada em Literatura e Linguística Portuguesa e Francesa. Publicou a sua primeira obra, Um 
Jogo Bastante Perigoso, em edição de autor, quando tinha 25 anos de idade. Nos vinte anos seguintes publicou 25 livros, o mais recente em 2017, com o título Estar Em Casa. Ana Bela Simões de Almeida explica esta imagem trabalhada como uma espécie da «obra metaliterária que reflete sobre o seu próprio sentido e estrutura, no decorrer da qual se vai construindo uma autobiografia literária, como uma personagem heteronímica que se dedicasse a constantemente re-escrever a própria história». (Almeida, Baltrusch, 2007: 12)

A imagem inocente e um pouco desajeitada da poetisa constitui parte indiscutível da obra de Adília Lopes, representando uma das metáforas do amor incompreendido, não correspondido, uma metáfora da solidão e da crueldade da vida. Como escreve Rosa Maria Martelo:

Somos sempre desarmados pela sua imagem de antipoeta e de menina. E, todavia, esta condição desarmada também é sua arma mais desarmante. Porque é ela que lhe permite ser especialmente eficaz na denúncia da hipocrisia, da crueldade, da cupidez e da estupidez do mundo em que vivemos. O modo como olha para a linguagem, a maneira como persistentemente a experimenta, questiona, desloca e analisa nada tem de fútil ou inocente. (Martelo, 2010: 215)

Numa crítica (Emídio Marquês, 2015: 1) ao seu livro mais recente, A Manhã, Adília Lopes foi chamada de anti-poeta, poeta-pop, poeta-kitsch, poeta-mulher-a-dias, poeta-anedota, etc. É interessante quantas imagens da poetisa podemos encontrar. E seria ainda mais interessante saber quais destas imagens são, afinal, criação da própria Adília. Ela mostra-se como uma tia que ficou para tia, deselegante, fora de moda, fora de época, um tanto arrogante, algo louca. Parece que esta imagem é bem trabalhada. Adília Lopes, aquela poetisa extremamente tímida, é capaz de dar longas entrevistas, até na televisão. Através do seu comportamento de anti-estrela, ela está a tornar-se uma estrela já hoje mitificada. Quantos poetas podem gabar-se de os seus versos se terem popularizado de tal modo que as pessoas na rua os usam sem saberem donde provêm, como é o caso do famoso «um dia tão bonito e eu não fornico», que se tornou uma frase recorrente para descrever um dia não «utilizado», do tempo que nos foge? No fundo, convenhamos, 
não andamos longe das expressões latinas «tempus fugit» ou «carpe diem»...

Osvaldo Silvestre vê na poesia de Adília Lopes «o sintoma simpático de uma espécie de apocalipse da linguagem poética em tempo de globalização e da pós-moderna desierarquização dos discursos». (Silvestre, 2001: 4) Muitos leitores poderiam concordar com esta afirmação, que, à primeira vista, parece assaz lógica e legítima. Mas a linguagem usada por Adília, ainda que por vezes crua e até cruel, não deixa de ser muito poética e cheia de emoções. Por outro lado, podemos admitir que se trata de uma poética um pouco apocalíptica, mas no sentido metafórico da palavra: apocalipse como uma mudança do rumo da poesia, de uma poesia que desnuda a existência humana, mais especificamente a existência da mulher, até aos ossos, até à medula. Nesse sentido, estamos perante uma poesia que é até, simultânea e surpreendentemente, bela e feia, de uma feiura profundamente humana. Mas é assim que ela consegue tocar o mais recôndito, o mais esquecido na alma.

\section{Caminhos do humor adiliano}

\section{Banalização dos grandes temas - Amor, Morte, Solidão}

O humor adiliano faz pensar no famoso «riso através das lágrimas» tchekhoviano, que mostra os defeitos e as fraquezas humanas com uma certa amabilidade e compreensão. Em Adília Lopes deparamos com poesia que nos faz rir e sentir angústia ao mesmo tempo. Os seus poemas, numa primeira leitura, podem até assustar ou, pelo menos, surpreender o leitor. Mas parece que a autora não sente a crueldade dos seus versos. Só quando pela primeira vez a editora fez associar a sua poesia a ilustrações da famosa pintora portuguesa Paula Rego, a poetisa ficou chocada:

No meu livro Sete rios e entrecampos falo de duas meninas a brincar às missas. E ela mostra na ilustração uma menina a dar a comunhão à outra, mas são aquelas meninas muito duras de Paula Rego, parecem assassinas. Chocou-me, até pensei que não me iria dar bem ao ver um livro 
com aquela capa. Sou capaz de ler tudo mas não sou capaz de ver tudo. As imagens chocam-me mais do que o texto. Percebi que a minha obra tem passagens chocantes, mas nunca senti isto, nem escrevo para chocar. Quando vejo as imagens da Paula Rego percebo melhor a recepção dos meus livros. É como se visse a leitura de um leitor materializada. (Rego, 2001: 9)

Adília atinge a banalização do amor, por exemplo, através de um dos seus motivos típicos: os desencontros. As tragédias, ou melhor: tragicomédias, dos desencontros são narradas de uma maneira natural, prosaica, dir-se-ia mesmo banal, e assim se atinge um efeito cómico e, ao mesmo tempo, trágico ou até horroroso. Talvez nesta poesia se encontre o melhor exemplo deste recurso poético:

\section{Os namorados pobres}

Os namorados pobres

O namorado dá

flores murchas

à namorada

e a namorada come as flores

porque tem fome

Não trocam cartas

nem retratos nem anéis

porque são pobres

(Lopes, 2009: 621)

Estas duas estrofes pareceriam retiradas de uma qualquer poesia amorosa, não se desse o caso de a namorada comer as flores oferecidas pelo apaixonado. Este detalhe parece derivar de uma das cenas grotescas de Charlie Chaplin que, como a poesia de Adília Lopes, também consegue criar imagens muito líricas, suscetíveis de causarem arrepio e fazerem rir ao mesmo tempo.

Mas um dia

têm muito medo

de se esquecerem 

um do outro
então apanham
um cordel
do chão
cortam o cordel
e trocam alianças
feitas de cordel
(Lopes, 2009: 621)

Aqui, por enquanto, o cordel representa a união amorosa entre os dois amantes, estando longe de possuir a conotação trágica que se seguirá sem tardar. O leitor pode ainda sentir emoção ou ficar até comovido. Os namorados, tão pobres que têm alianças de cordel, representam um motivo muito romântico. $\mathrm{O}$ medo de se esquecerem um do outro mostra o problema da falta de comunicação nas relações humanas, que é reforçado na estrofe seguinte.

Não podem

combinar encontros

porque não têm

número de telefone

nem morada

assim encontram-se

por acaso

e têm medo

de não se voltarem

a encontrar

(Lopes, 2009: 621)

Volta, pois, o motivo da falta de comunicação, que escalará até uma solução infeliz, mas de novo romântica - nunca saírem do mesmo sítio para não se perderem, como se ficassem encarcerados numa prisão imaginária.

$\mathrm{O}$ acaso

não os favorece

Decidem nunca sair 
do mesmo sítio

e ficarem sempre juntos

para não se perderem

um do outro

(Lopes, 2009: 621)

Mas esta solução romântica tornar-se-á uma solução trágica quando os dois decidem enforcar-se, por não conseguirem encontrar um só sítio que lhes possa pertencer, a que possam chamar seu. Se não fosse um poema de Adília Lopes, até poderíamos entendê-lo como um texto que pretendesse denunciar desigualdade e injustiça social.

Procuram um sítio

mas todos os sítios

têm dono

ou mudam de nome

Então retiram

dos dedos

os anéis de cordel

atam um anel

ao outro

e enforcam-se

(Lopes, 2009: 621)

Até este momento poderíamos achar este poema bastante lírico, até romântico. Poderíamos talvez só notar uma certa tendência para o prosaico. Mas agora tudo muda. A morte dos dois amantes é banalizada até ao ridículo.

Mas a namorada

tem de esperar

pelo namorado

porque o cordel

só dá par[a] um

de cada vez

O namorado

descansa à sombra 
da figueira

e a namorada

baloiça

na figueira

O dono da figueira

zanga-se

com os namorados pobres

porque julga

que estão a roubar figos

e a andar de baloiço

(Lopes, 2009: 621)

O leitor não sabe se há de rir ou chorar. Pelo menos, sente um arrepio a par de um sorriso amargo. O ridículo da conclusão do poema faz realçar a tragédia do desencontro amoroso e o grande tema - morrer por amor. A imagem de um enforcado a baloiçar na figueira e a outra figura a descansar à sombra pertence às imagens que não se esquecem. Faz, mais uma vez, pensar nos quadros da pintora Paula Rego, e não é de estranhar. Tanto na poesia da Adília Lopes como na pintura de Paula Rego a morte tem um papel principal, um pouco escondido, misterioso, não falado/visível, mas óbvio. Depois de receber o pedido da editora para ilustrar o livro Obra, Paula Rego ficou chocada aquando da primeira leitura:

Só no verão passado é que li a poesia da Adília Lopes. O editor enviou-me alguns livros para que eu ilustrasse a obra. Comecei a ler e fiquei pasmada por haver alguém que escrevia aquelas coisas... Adília Lopes é de um grande romantismo - por exemplo, diz: Ah, quem me dera um vestido que me queimasse - e ao mesmo tempo de um grotesco e de um cómico transbordantes. Para mim, o grotesco é belo, o grotesco é de uma grande ternura. E ela está cheia de ternura e de compaixão, mas não é lamechas. A maldade é reconhecida mas não é praticada, sem ser maledicente reconhece o que é importante no mal. A maldade é o outro lado das coisas boas. Dizer que é uma tímida que se desenrasca é uma boa definição para a Adília Lopes. (2001: 9) 


\title{
Banalização das obras literárias mitificadas
}

Exemplo da banalização das obras e personagens literárias mitificadas é o próximo poema, que reconstrói a história de Mariana Alcoforado e do Marquês de Chamilly. Estão entre as personagens intertextuais prediletas de Adília Lopes. Este poema banaliza, de uma maneira irónica e prosaica, o desencontro destas duas personagens, atribuindo à monja uma escrita ilegível. $\mathrm{O}$ poema é escrito como uma carta do próprio Marquês de Chamilly a Mariana Alcoforado. A carta imaginária é bastante impessoal, despida de qualquer paixão, chegando até a lembrar uma carta oficial, redigida por um qualquer funcionário público, por exemplo dos correios. Além disso, o facto de Chamilly nunca conseguir ler as cartas amorosas escritas por Mariana, muda completamente toda a história que conhecemos.

\section{O Marquês de Chamilly a Mariana Alcoforado}

\author{
Minha senhora deve ter \\ uma coisa muito urgente e capital \\ a dizer-me \\ porque me tem escrito muito \\ e muitas vezes \\ porém lamento dizer-lho \\ mas não percebo \\ a sua letra \\ já mostrei as suas cartas \\ a todas as minhas amigas \\ e à minha mãe \\ e elas também não percebem bem \\ não me poderia dizer \\ o que tem a dizer-me \\ em maiúsculas? \\ ou pedir a alguém \\ com uma letra mais regular \\ que a sua
}


que me escreva

por si?

como vê tenho a maior vontade

em lhe ser útil

mas a sua letra minha senhora

não ajuda

(Lopes, 2009: 87)

Assim, toda a tragédia amorosa se transforma num simples equívoco: de repente, o cavaleiro não é, por assim dizer, um malandro que abandonou a monja, mas sim um cavalheiro que está a fazer todo o possível para perceber e ajudar a pobre senhora. Desta maneira a história perde toda a componente trágica, toda a paixão, ou seja, perde tudo o que fez dela um bestseller da época. E a pobre Mariana Alcoforado sai desta versão sobretudo como uma disgráfica histérica. Tudo o que era poético nesta obra epistolográfica se tornou banal e prosaico. E, subitamente, a solidão da monja tornou-se ainda mais desesperada - desesperada solidão prosaica. Talvez pudéssemos até considerar esta locução como a caraterística mais apropriada para a obra de Adília Lopes.

\section{Considerações finais}

A poesia de Adília Lopes tem o seu encanto indiscutível, o que podemos deduzir, quanto mais não seja, pelo número de livros esgotados e traduções (para inglês, francês, alemão, espanhol e italiano). É uma poesia bastante lógica, simples nos temas, assaz prosaica e compreensível. Muitos dos leitores podem identificar-se com alguns aspetos do sujeito lírico dos poemas adilianos.

A personagem principal, a velha menina cómica e, ao mesmo tempo, deplorável, apresenta-nos os temas importantes da vida e da morte, banalizados ao ponto de parecerem inventados por uma menina da escola primária. Nas suas narrações acentua tantos detalhes que o foco narrativo fica completamente escondido ou, melhor, esquecido, senão mesmo incompreendido. 
Todavia, a imagem que Adília cria para o seu sujeito lírico é a imagem perfeita de uma personagem literária ou, antes, metaliterária. É como se a Alice do País das Maravilhas envelhecesse e continuasse a viver lá. É lógico que ficou para tia, pois no País das Maravilhas não há homens com quem casar, a não ser talvez o Chapeleiro Maluco, mas que é maluco demais e cujo respeito perante o tamanho da Alice não lhe permite uma relação amorosa com ela. As metamorfoses incessantes dos habitantes do País das Maravilhas, tanto humanas como animais, explicam bem o facto de Alice se sentir insegura e incerta no mundo que a rodeia. Também a sensação de solidão e isolamento parece, nesta perspetiva, completamente lógica e legítima. Se lermos a poesia da Adília Lopes sob este novo contexto, ela ganha conotações mais amáveis e compreensíveis. De repente, não levamos as histórias e as personagens tão a sério e podemos compreendê-las de uma maneira mais feérica e metafórica. Mas existe mais um lado da poesia adiliana, mais escondido e mais obscuro: a vertente grotesca, que provoca, ao mesmo tempo, riso e arrepio. Podemos muitas vezes ver este grotesco descrito como sublime ou cómico, mas, do nosso ponto de vista, este cómico é, acima de tudo, grotesco de dor. É um grotesco muito carnal, muitas vezes ligado ao erótico, ao corpo ou à morte. Sobre a dualidade deste recurso artístico na poesia escreve o já citado Borges:

Os cultores retardários da estética classicista talvez quisessem negar a existência de uma musa do grotesco. $\mathrm{O}$ falso gosto ou a ausência dele corresponderia a um poeta abandonado pelo sopro da inspiração e da memória. Supõe-se que um poeta de fantástico, como Fausto, só possa invocar o demônio, ou que um poeta maldito contente-se com suas prostitutas a sugerir poemas pornográficos. Que a mesma musa dá ao gênio o ímpeto de conciliar o grotesco e o sublime. (Borges, 2002: 7)

Conciliação é a palavra que designa com maior precisão o sentimento após a leitura da obra de Adília Lopes. Apesar de todas as sensações de horror ou arrepio que a poética adiliana possa suscitar, temos vontade de aconchegar aquela tia desajeitada, aquela Alice no País das Maravilhas envelhecida e dizer como Roland Barthes: Devemos sempre defender em nós aquilo de que os outros riem. 


\section{Referências bibliográficas}

ALMEIDA, S. de, BALTRUSCH, B. (2007), Entre o Essencialismo Rural de Fisteus e o Pós-modernimso urbano de Lisboa - uma Comparação (Im) Possivel entre Lupe Gómez e Adília Lopes, University of Santa Barbara, Universidade de Vigo.

BORGES, B. I. (2010), "O (mau) gosto e o grotesco", Mars Gradivus Revista do Laboratório de Psicanálise e Aprendizagem, 1(1), [on-line] https:// www.ufrgs.br/psicopatologia/lpa/bento_01.htm - 12.05.2018.

EMÍDIO MARQUÊS, J. (2015), Adília Lopes: Louca da casa, [on-line] https://observador.pt/2015/04/27/adília-lopes-a-louca-da-casa/ - 30.05.2018.

ESPANCA, F. (2009), Obra Poética, vol. I, Presença, Lisboa.

Peça Mana Solta a Gata em estreia no Teatro do Bairro, [on-line] https://www. youtube.com/watch? $\mathrm{v}=\mathrm{Q} 7 \mathrm{kQ}$ cbEo5M.

LOPES, A. (1999), Sete rios e entrecampos, \& etc, Lisboa.

LOPES, A. (2000), Obra, Mariposa Azul, Lisboa.

LOPES, A. (2001), Quem quer casar com a poetisa?, Quasi, Vila Nova de Famalição.

LOPES, A. (2009), Dobra, Assírio Alvim, Lisboa.

LOPES, A. (2015), A Manhã, Assírio Alvim, Lisboa.

MARTELO, R. M. (2000), "Recensão crítica a 'Obra', de Adília Lopes", Revista Colóquio/Letras. Recensões Críticas, 157/158, pp. 398-401.

MARTELO, R. M. (2004), "Martelo Adília Lopes - ironista", SCRIPTA, Revista do Programa de Pós-graduação em Letras e do Cespuc, 8(15/2), Pontifícia Universidade Católica de Minas Gerais, pp. 106-116.

MARTELO, R. M. (2010), "As Armas Desarmantes de Adília Lopes", Didaskalia, 2, pp. 207-222, [on-line] https://repositorio.ucp.pt/bitstream/10400.14/10150/1/V04002-207-222.pdf - 10.05.2018.

MARTELO, R. M. (2010), “Contra a crueldade, a ironia” em: Martelo, R. M., A forma informe. Leituras de poesia, Assírio Alvim, Lisboa.

REGO, P. (2001), "Paula Rego sobre Adília Lopes: No grotesco há muita ternura”, Suplemento Mil Folhas (Público).

SILVESTRE, O. M. (2001), Adília Lopes espanca Florbela Espanca, Sete Letras, Rio de Janeiro. 